\title{
慢性的な水ストレス下での臭柏の生育経過
}

\author{
温 国勝 ${ }^{1}$ 図子美和子 ${ }^{2} \cdot$ 坂本圭児 ${ }^{3} \cdot$ 王 $\quad$ 林和 ${ }^{4} \cdot$ 吉川 賢 ${ }^{3}$
}

\section{Study on Growth of Sabina vulgaris under Long Term Water Stress}

\author{
Wen, Guo Sheng ${ }^{1}$, Zushi, Miwako², SAKamoto, Keiji ${ }^{3}$, WAng, Lin $\mathrm{He}^{4}$ \\ and YosHIKAWA, Ken ${ }^{3}$
}

\begin{abstract}
要旨
中国内蒙古自治区毛烏素沙地に自生する臭柏（Sabina vulgaris）の耐乾性を明らかにす ることを目的として, 3 年間実験室で鿬耕栽培によって苗木に水ストレスを加えて生育さ せた。培養液にポリエチレングリコールを加えて浸透圧を調整することで 3 段階の水スト レス（対照, 弱, 強）を与えた。伸長成長は 6 月から 7 月の高温期に一時停止した。その 停止期間は水ストレスが強いほど長くなる傾向があった。各処理区 16 個体のうち対照区 はすべての個体が 3 年間生存したが， 2 つのストレス区はともに 1 年目に $25 \%$ が枯死し， 強ストレス区は 2 年目にさらに $25 \%$ の個体が枯死した。慢性的な水ストレスに対する適応 には比較的長い期間を要し，その間に成長の停止や枯死が起こった。生存個体や枯死個体 の形状やサイズについて論議した。
\end{abstract}

\section{1. はじめに}

植物は体内の水が減ってくると代謝や物質の移 動,さらには成長などに影響を受ける。特に乾燥し た環境に生育する植物ではそうした水ストレスを受 ける機会が多く，植物の生存に対する大きな制限要 因となっている。そのため, 蒸散を制限して水分消 失をできるだけ少なくしたり, 根の吸水力を高めて 水分の獲得と供給を確保したり，あるいは代謝機能

キーワード：慢性の水ストレス, 臭柏, ポリエチレングリ コール

Key words : Long term water stress, Sabina vulgaris, Polyethylene glycol

1 岡山大学大学院自然科学研究科

Grad. Sch. of Natural Sci. and Technol., Okayama Univ.

2 香川県庁

Kagawa Prefecture

3 岡山大学農学部

Fac. of Agric., Okayama Univ.

4 内蒙古農業大学

Inner Mongoria Univ. of Agric.
が障害を受ける含水率をできるだけ低く下げるとい つた方法で, 植物は一時的な水不足だけでなく, 慢 性的な水ストレスに適応している (LARCHER, 1995; 酒井，1995）。特に, 砂漠化の進んだ土地で樹木を植 栽して緑化を進めようとするような場合, 植栽地が どのような水不足の状態にあるのかということにつ いての解析 (RUNDEL and JARRELL, 1989) と同時に, 樹木自身がどういった耐乾性を持っているのかを知 っている必要がある（FITTER and HAY, 1981)。し かし, 半乾燥地の水分状態やそこに生育する樹木の 耐乾性についてはまだ十分に解明が進んでいるとは 言えない。

本研究は, 砂漠化が進行し, 流砂固定と緑化が急 がれている中国内蒙古自治区のオルドス高原（毛鳥 素沙地）(治沙造林学編委会, 1981; 北京大学地理系 ら，1983）に自生する臭柏 (Sabina vulgaris)（王ら， 1.983 ；徳岡，1995）を，慢性的水ストレス条件下で 3 年間にわたって生育させ, その生育経過から耐乾 性樹木の水ストレス耐性に関する生理・生態的特性 を調べた。 


\section{2. 実験材料と方法}

\section{1 供試木と礫耕栽培装置}

苗木は中国内蒙古林学院 (呼和浩特市) のキャン パス内に生育する 10 年生の臭柏から $2 \sim 3$ 年生の枝 を採取し, 1994 年 6 月に岡山大学農学部構内のガラ ス室内で挿し木を行った。6月から 9 月までの日中 の平均気温は $31.5 \pm 6.0^{\circ} \mathrm{C}$ (平均士標準偏差, 以下同 様), 湿度は $49.3 \pm 20.0 \%$ で, 夜間はそれぞれ $24.7 \pm$ $3.2^{\circ} \mathrm{C}, 75.1 \pm 13.0 \%$ あっった。発根した 48 個体を, 図 1 に示す礫耕栽培装置 (MORIMOTO and YosHIKAWA, 1998)へ 1994 年 10 月 18 日に植栽した。植栽 した苗木のサイズは表 1 に示す。装置内では 30 分 に 1 回ずつ $80 l$ の Hogland 培養液を 5 分間循環さ せた。

\section{2 ストレス処理と測定}

1995 年 3 月 1 日から培養液にポリエチレングリ コール (PEG, 分子量 6,000) を加え, 浸透ポテンシ ヤルを $-0.02 \mathrm{MPa}$ (対照区), $-0.10 \mathrm{MPa}$ (弱スト レス区)， $-0.34 \mathrm{MPa}$ (強ストレス区) の 3 段階に

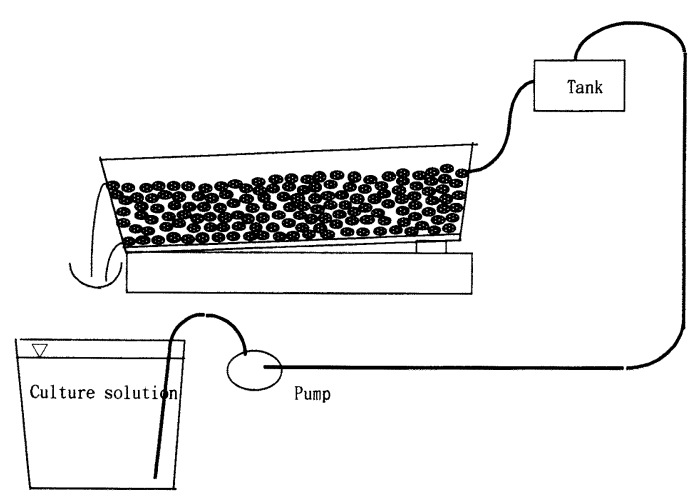

図 1 碟耕栽培装置

Fig. 1 Water cultivation system
調節した。それぞれの值を $\mathrm{pF}$ 值に換算すると, 対 照区は 2.3 , 弱ストレス区は 3.0 , 強ストレス区は 3.5 であった。毛鳥素沙地で臭柏が生育している砂 丘の $\mathrm{pF}$ 值は 2.8 3.8 であり (増田ら, 1988), 弱ス トレス区と強ストレス区は毛烏素沙地の砂丘上とほ ぼ同じ状態であった。

分子量の小さな PEG の場合, 植物に吸収された り (JANEs, 1974; JACOMINI et al., 1987), 葉 (WEST et al., 1980) や細根（JACKSON, 1962）の生長に影 響があるという報告もあるが, 多くの研究では (MEXAL et al., 1975; KRIZEK, 1985) それらの影響 はごく弱いものであり，土壤水分そのものを調節す るよりも正確な水ストレスを与えることができると して, 培養液の浸透圧を安定に調節するために $\mathrm{PEG}$ は利用されてきている。ZWIAZEK and BLAKE (1989, $1990 \mathrm{a} ， 1990 \mathrm{~b})$ は分子量 3,350 の PEGによって blackspruce の浸透ストレス耐性についての研究を 行っている。本実験では分子量 6,000 のものを用い たので, PEGによる生育阻害は少ないものと考えら れる。

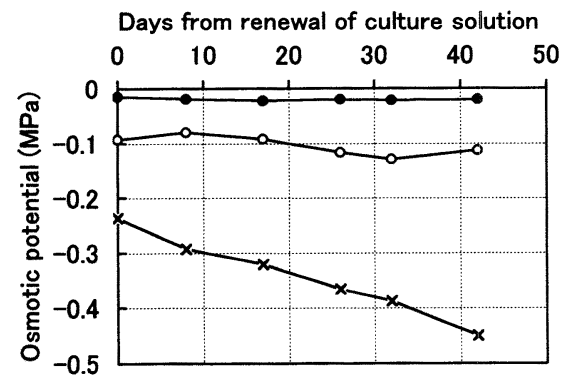

図 2 培養液交換後の浸透ポテンシャルの変化

○:対照区, $\bigcirc$ : 弱ストレス区, $\times$ : 強ストレス区

Fig. 2 Changes in osmotic potential of culture solution after renewal

: control, $\bigcirc$ : light stress, $\times$ : strong stress

表 1 植栽した苗木の本数, 苗高, 地際直径

Table 1 Sizes of planted cuttings

\begin{tabular}{lccc}
\hline & $\begin{array}{c}\text { Number of } \\
\text { cuttings }\end{array}$ & $\begin{array}{c}\text { Height }(\mathrm{cm}) \\
\text { Average } \pm \mathrm{SE}\end{array}$ & $\begin{array}{c}\text { Basal diameter }(\mathrm{mm}) \\
\text { Average } \pm \mathrm{SE}\end{array}$ \\
\hline Control & 16 & $15.4 \pm 0.6 \mathrm{a}$ & $2.33 \pm 0.08 \mathrm{a}$ \\
Light stress & 16 & $15.0 \pm 0.7 \mathrm{a}$ & $2.24 \pm 0.08 \mathrm{a}$ \\
Strong stress & 16 & $15.2 \pm 0.6 \mathrm{a}$ & $2.36 \pm 0.04 \mathrm{a}$ \\
\hline
\end{tabular}

Figures with the same letters are not significantly different among treatments at the 0.05 significance level by ANOVA. 
表 2 苗高と地際直径の 1 年間の生長量

Tabe 2 Annual increments of height and basal diameter

\begin{tabular}{|c|c|c|c|}
\hline \multirow{2}{*}{ Treatment } & \multicolumn{3}{|c|}{ Average $\pm \mathrm{SE}$} \\
\hline & 1995 & 1996 & 1997 \\
\hline \multicolumn{4}{|c|}{ Height increment $(\mathrm{cm} / \mathrm{yr})$} \\
\hline Control & $24.1 \pm 2.1 \mathrm{a}$ & $22.6 \pm 4.4 \mathrm{a}$ & $16.8 \pm 2.2 \mathrm{a}$ \\
\hline Light stress & $13.7 \pm 2.9 \mathrm{~b}$ & $11.1 \pm 2.6 \mathrm{ab}$ & $10.2 \pm 1.8 \mathrm{a}$ \\
\hline Strong stress & $16.0 \pm 3.3 \mathrm{ab}$ & $6.8 \pm 1.4 \mathrm{~b}$ & $15.1 \pm 2.1 \mathrm{a}$ \\
\hline \multicolumn{4}{|c|}{ Diameter increment $(\mathrm{cm} / \mathrm{yr})$} \\
\hline Control & $2.31 \pm 0.19 \mathrm{a}$ & $2.97 \pm 0.43 \mathrm{a}$ & $1.41 \pm 0.11 \mathrm{a}$ \\
\hline Light stress & $1.13 \pm 0.17 \mathrm{~b}$ & $1.12 \pm 0.25 \mathrm{~b}$ & $1.04 \pm 0.20 \mathrm{a}$ \\
\hline Strong stress & $1.70 \pm 0.19 \mathrm{ab}$ & $0.99 \pm 0.23 \mathrm{~b}$ & $0.94 \pm 0.19 \mathrm{a}$ \\
\hline
\end{tabular}

Figures with the same letters are not significantly different among treatments (Scheffé, $p<0.05$ ).

培養液は 6 週間ごとに更新し，蒸発や養分吸収に よる組成変化の影響を除いた。図 2 に培養液の交換 直後から次の交換までの浸透ポテンシャルの変化を 示す。最も変化の大きかった強ストレス区では培養 液を交換した直後はー0.24 MPa であったものが, 6 週間後にはー0.45 MPa まで減少した。

各個体の苗高は 7 10 日ごとに測定し, 地際直径 は成長期の前後（3 月，10月）で測定した。

\section{3. 結果}

3.1 伸長成長量

表 2 に各処理区の苗木の 1 年間の伸長成長量（平 均值土標準誤差）を示す。処理 1 年目と 2 年目は処 理間に有意差 (分散分析)が認められたが（ $p_{\text {(1995 年) }}$ $\left.=0.026, p_{\text {(1996 年) }}=0.008, p_{(1997 \text { 年 })}=0.108\right)$, Scheffé の多重比較検定を行ったところ, 弱ストレス区と強 ストレス区の間ではどの年も有意差は認められなか つた。統計的に有意ではないが，いずれの年も対照 区は両ストレス区よりも大きな成長を示す傾向が認 められた。

苗高の 1 日当たりの伸長成長量を図 3 に示す。処 理 1 年目はどの処理区でも 3 月中旬から伸長成長が 始まり，4月下旬に成長のピークを示した。また，対 照区ではほとんどの個体で 7 月下旬から 9 月上旬に 2 回目のピークが認められた。弱ストレス区と強ス トレス区でも半数ほどの個体で 7 月から 8 月に 2 回 目のピークを示した。

処理 2 年目の対照区では 3 月中旬に成長を開始し たあと, 10 月下旬までほとんどの個体がほぼ連続し て伸長成長を続けた。一方，弱ストレス区と強ス卜 レス区では， 1 年目と同椂に，一部の個体では 2 回
の成長ピークが認められたが, 1 回目と 2 回目の成 長期の間に全く伸長成長しない期間が認められた。

処理 3 年目はごく一部の個体を除いて，どの処理 区でも 3 月中旬から 5 月下旬の 1 回だけ旺盛な成長 をし， 7 月以降は伸長成長が認められなかった。

\section{2 肥大成長}

表 2 に苗木の 1 年間の肥大成長量の平均值士標準 誤差を示す。伸長成長量の場合と同様に，分散分析 の結果，処理 1 年目と 2 年目で処理間に有意差が認 められた $\left(_{(1995 \text { 年 })}=0.001, p_{(1996 \text { 年 })}=0.0003, p_{\text {(1997 年) }}\right.$ $=0.109) 。$ Scheffé の多重比較検定を行ったところ, 対照区は処理 1 年目は弱ストレス区と，2 年目は両 処理区と有意差が認められた（対照区・弱ストレス 区: $p_{(1995 \text { 年 })}=0.001, p_{(1996 \text { 年 })}=0.003$, 対照区・強又 トレス区 $\left.: p_{(1995 \text { 年 })}=0.099, p_{(1996 \text { 年 })}=0.002\right)$ 。しか し, 弱ストレス区と強ストレス区の間には 3 年とも 有意差は認められなかった。

\section{3 形状比}

以上のように，伸長成長，肥大成長とも水ストレ スの影響を受けたが，その両者の関係をみるため， 水ストレス処理開始時 (1995 年 3 月) とそれぞれの 年の最後の時点の苗高 $(H)$ /地際直径 $(D)$ の値を 図 4 に示す。どの処理区でも年とともに徐々に地際 直径に対して苗高が大きくなる傾向が認められた。 また，いずれの場合も，分散分析の結果，処理区間 で統計的に有意な差は認められなかったが，処理 1 年目の終わりから既に水ストレスが強いほど地際直 径に対する高さの割合が低くなる傾向があり，その 関係は 3 年間ほほ変わらなかった。ただし, 強ス卜 レス区で $H / D$ が 3 年目に大きく増加したが，これ は後述するように，その年に 4 個体が枯死したこと 

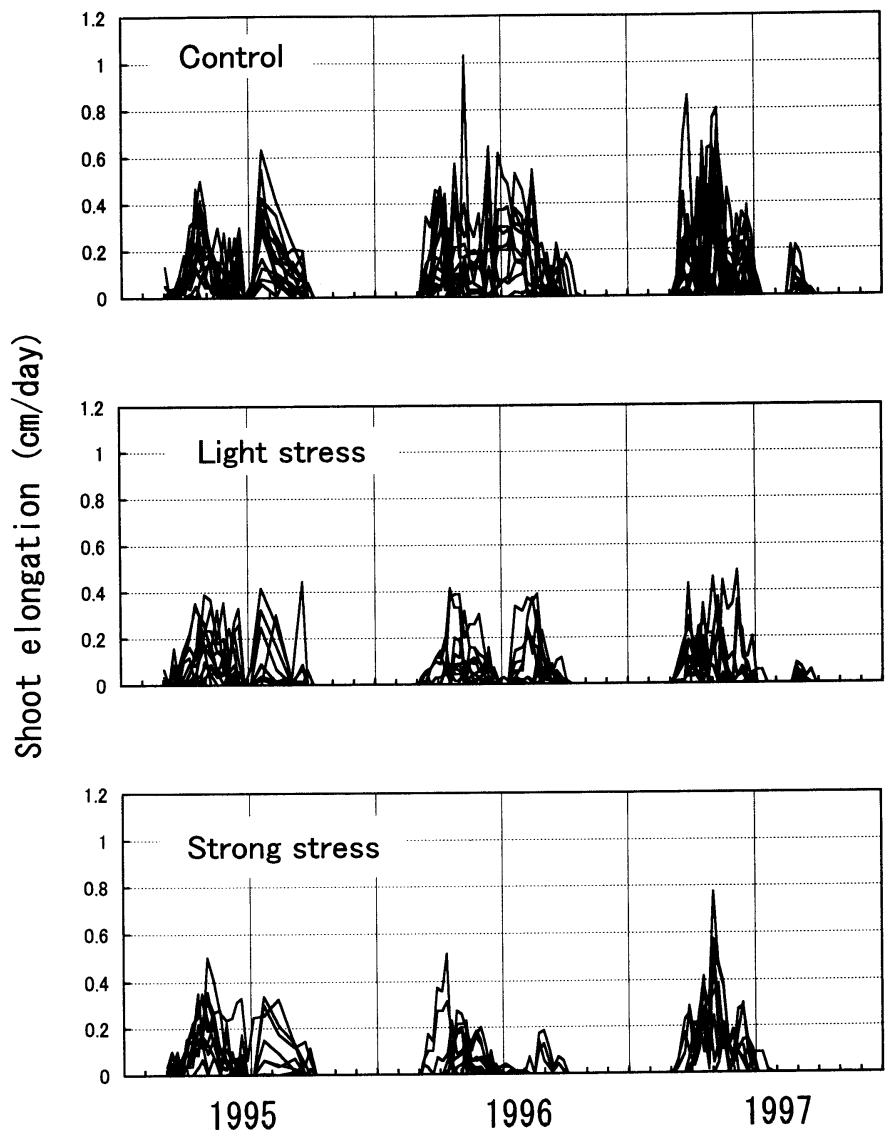

図 33 年間の伸長成長の季節的変化

Fig. 3 Seasonal changes in height growth for three years

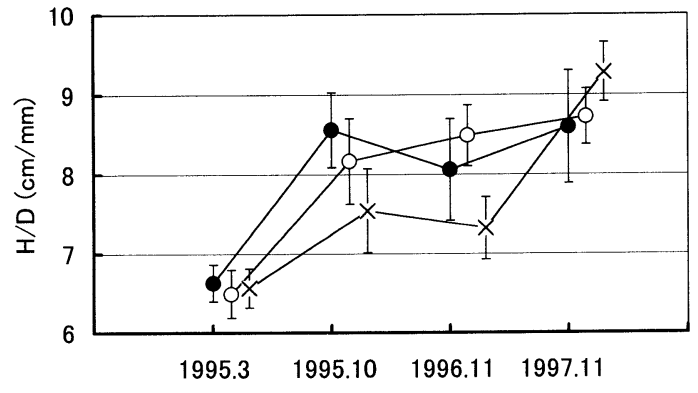

図 4 苗高/地際直径の季節的変化

○: 対照区, $\bigcirc$ : 弱ストレス区, $\times$ : 強ストレス区

Fig. 4 Seasonal changes in height/basal diameter ratio $(H / D)$

: control, $\bigcirc$ : light stress, $\times$ : strong stress

によるものである。すなおち，処理 3 年目に枯死し た個体の 2 年目の終わりの苗高は $23.8 \pm 4.0 \mathrm{~cm}$ (平 均值士標準誤差)で, 3 年目も生存していた個体の平 均苗高 $45.7 \pm 5.3 \mathrm{~cm}$ より有意に低かった（平均值
の差についての $t$ 検定 $: p=0.02)$ 。そのため, 成長 の劣っていて $H / D$ の小さな個体が枯死したために 見かけ上は平均值が増加したといえる。

\section{4 累積枯死率}

図 5 に 1995 年のはじめの個体数を基準とした 3 年間の各処理区での苗木の累積枯死率を示す。対照 区では 3 年間全く枯死個体は出現しなかったが，弱 ストレス区と強ストレス区では処理 1 年目に 4 個体 が枯死した。さらにこの時点で，強ストレス区では 生存しているが枝先が枯れ始めている個体がみら れ, 2 年目に新たに 4 個体が枯死した。しかし, 処理 3 年目にはどの処理区でも枯死個体は出現しなかっ た。

それぞれの枯死個体の経過についてみると（表 3), 弱ストレス区で枯死した 4 個体のうちの 2 個体 は 1 年目の 4 月中下旬に先枯れが始まり，6月上旬 に枯死した。それとほほ同じ時期に残りの 2 個体で 先枯れが始まり，約 1 力月後に枯死した。先枯れが 
表 3 枯死個体の生育経過

Table 3 Height growth of cuttings died in 1995 and 1996

\begin{tabular}{|c|c|c|c|c|c|c|c|c|}
\hline \multirow{3}{*}{ Treatment } & \multirow{3}{*}{ Tree } & \multirow{3}{*}{ No. } & \multirow{3}{*}{$\begin{array}{l}\text { Start of } \\
\text { die back }\end{array}$} & \multirow{3}{*}{$\begin{array}{c}\text { Day of } \\
\text { death }\end{array}$} & \multicolumn{4}{|c|}{ Height increment $(\mathrm{cm})^{*}$} \\
\hline & & & & & \multicolumn{2}{|c|}{1995} & \multicolumn{2}{|c|}{1996} \\
\hline & & & & & Dead** & Alive $e^{* * *}$ & Dead & Alive*** \\
\hline \multirow[t]{4}{*}{ Light stress } & 1995 & 1 & $4 / 14-21$ & $5 / 27-6 / 2$ & 0.5 & 2.3 & & \\
\hline & & 2 & $4 / 21-27$ & $5 / 27-6 / 2$ & 1.8 & 3.2 & & \\
\hline & & 3 & $6 / 2-9$ & $7 / 5-12$ & 13.3 & 8.4 & & \\
\hline & & 4 & $6 / 9-16$ & $7 / 5-12$ & 11.8 & 9.0 & & \\
\hline \multirow[t]{8}{*}{ Strong stress } & 1995 & 1 & $6 / 16-23$ & $7 / 24-31$ & 12.5 & 10.8 & & \\
\hline & & 2 & $6 / 24-7 / 1$ & $9 / 15-22$ & 4.6 & 11.0 & & \\
\hline & & 3 & $7 / 5-12$ & $9 / 15-22$ & 8.3 & 11.2 & & \\
\hline & & 4 & $7 / 5-12$ & $9 / 15-22$ & 11.8 & 11.2 & & \\
\hline & 1996 & 5 & $3 / 4-11$ & $3 / 25^{-4 / 1}$ & $(5.0)$ & & 0.0 & 0.0 \\
\hline & & 6 & $6 / 3-10$ & $7 / 15-29$ & $(1.0)$ & & 0.0 & 6.6 \\
\hline & & 7 & $7 / 29-8 / 5$ & $8 / 19-26$ & (11.8) & & 3.0 & 7.7 \\
\hline & & 8 & $9 / 16-23$ & $11 / 4-11$ & $(10.7)$ & & 4.5 & 9.2 \\
\hline
\end{tabular}

* Height increment of cutting on the day of die back start from the beginning of growing season. ${ }^{* *}$ Figure in parentheses is height increment at the end of $1995 .{ }^{* * *}$ Mean for all other healthy cuttings on the day of die back start.

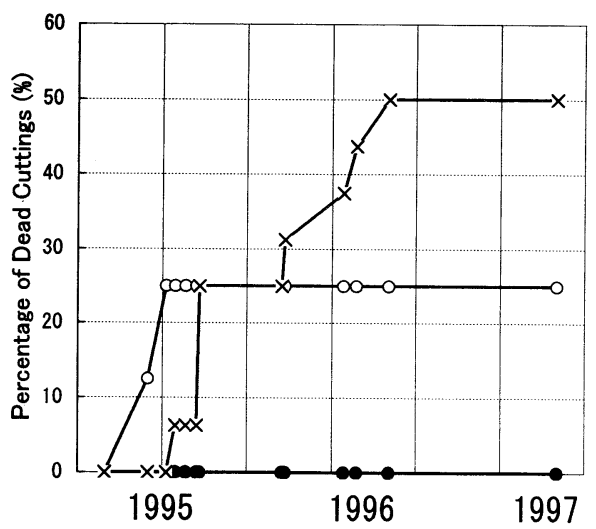

図 5 枯死率の変化

○ : 対照区, $\bigcirc$ : 弱ストレス区, $\times$ : 強ストレス区

Fig. 5 Seasonal changes in percentage of accumulative number of dead cuttings

: control, $\bigcirc$ : light stress, $\times$ : strong stress

始まったときの伸長成長量でみると, はじめの 2 個 体は他の生存個体よりも成長が劣っていたが，次の 2 個体はよく成長していた。

一方，強ストレス区で先枯れが始まったのは弱ス トレス区より遅く，6月中下旬から 7 月上旬であっ て, 7 月下旬に 1 個体, 9 月中旬に 3 個体が枯死し た。 2 年目は 3 月上旬, 6 月上旬, 7 月下旬, 9 月下
旬に 1 個体ずつ先枯れが始まり，それぞれ 3 月下 旬， 7 月下旬， 8 月下旬，11月上旬に枯死した。その 結果, 累積枯死率は 1 年目で $25 \%$ となり, 2 年目に は $50 \%$ とった。枯死した 8 個体のうちの 6 個体は 先枯れが始まった時点での生存個体の平均よりも伸 長成長は劣っていた。また， 2 年目に枯死した個体 では 1 年目の成長もきわめて悪いものであった。

\section{4. 考察}

臭柏が天然分布している毛鳥素沙地の年降雨量は 平均 $360 \mathrm{~mm}$ と大変乾燥しており（神近・山本, 1986), 現地では日平均気温が $10^{\circ} \mathrm{C}$ を越える 5 月中 旬から臭柏の伸長成長が始まり，9月か 10 月に成長 を終了する（蘇・李，1987：李ら，1996）。本実験は ガラス室内で行ったために，かなり高温条件のもと での生育となった。その結果, 臭柏の伸長成長は 3 月に始まり，10月まで続いた。その間，水ストレス には敏感に反応して, 伸長成長だけでなく肥大成長 も抑制されることが示唆された。すなわち, 肥大成 長も伸長成長も明らかに水ストレス処理区で少なく なった（表 2)。ただし, 水ストレスの強さの成長量 そのものへの影響についてはその違いは必ずしも明 瞭なものではなかった。

季節的変化が認められた伸長成長について成長が 
一時停止する期間をみてみると, 1 年目はどの処理 区でも 2 週間程度であったが， 2 年目は対照区で停 止する時期が全く認められなかったのに対して, 弱 ストレス区で約 3 週間, 強ストレス区で約 8 週間続 いて，ストレスが強いほど長くなった。3 年目も同 じ傾向がみられ, 弱ストレス区で約 6 週間, 強スト レス区では 7 月 8 日以降成長は停止した（図 3)。

6 月中旬から 7 月中旬の成長が一時停止する時期 は一番高温の季節であった。対照区では 2 年目のこ の時期に成長が止まっていないので, 高温の時期で も, 生育環境が許せば, 内的な生理的メカニズムに よって成長の休止をしなければならないということ はないようであった。むしろ 5 月から 8 月の降雨に よって生長量が増加する場合も観察されている(王, 未発表)。したがって, 1 年目は高温ストレスに移植 の影響が加わって, どの処理区でも成長の一時停止 が起こり，2 年目以降は水ストレスがない場合には 高温ストレスに耐えて成長を続けることができた が, 水ストレスを受けた場合には, その強さに比例 して高温ストレスによる成長の一時停止の期間が長 くなったと考えられる。スギでも同様の水ストレス の影響が認められている（王ら，1989）。

苗木の枯死の経過については明らかに水ストレス 処理によって違いが認められた（図 5)。すなわち, 処理 1 年目は弱ストレス区と強ストレス区の枯死率 は同じであった。弱ストレス区では水ストレス処理 2 年目以降は枯死がなかったのに対し, 強ストレス 区では処理 2 年目も枯死が続いた。しかし, 処理 3 年目には枯死は起こらなくなった。これは, 弱スト レス区では 2 年目で水ストレスに順応したのに対し て, 強ストレス区では順応するまでにさらに長い時 間がかかったことを示唆している。ちなみに, 1 年目 に枯死した個体を 11 月に掘り取ったところ, 根系 の発達がきわめて悪く, 植栽時とほとんど同じ状態 であった。そこでそうした枯死の経過を枯死個体の サイズから見ると次のようになった。

弱ストレス区，強ストレス区とも，1年目は成長 の遅れた個体と伸びすぎてバランスが悪くなった個 体が枯死した。その結果, 弱ストレス区では 1 年目 に死なずに生き残った個体はバランスが良かったの で, 次の年には枯れが起こらなかったと考えられ る。一方, 強ストレス区では, 2 年目になっても引き 続くストレスの積み重なりのため成長が悪くなり, 順次枯死した。そのため枯死個体の発生時期は一定
せず， 1 年を通じてゆっくりと枯死が起こり，いろ いろな時期に枯死個体が出現した（図 5)。つまり, 強ストレス区では処理 1 年目は短期間に一度に枯れ が発生し, 処理 2 年目は断続的に枯れが発生した。 また, 処理 1 年目は, 弱ストレス区は成長期間に, 強ストレス区は伸長成長が終わってから枯死した。

このことは枯れはじめから完全に枯死するまでの 期間の長さにも反映された。すなわち, 弱ストレス 区の 4 個体とも枯れはじめから完全に枯死するまで の期間は約 30〜40 日であった。一方，強ストレス区 の場合, 早ければ, 弱ストレス区と同じ 40 日程度で あったが，多くは70日以上かかった。しかし，2 年 目はいずれも約 25〜55 日であった。

\section{引用文献}

1) 治沙造林学編委会：治沙造林学, 中国林業出版社, 北京, 323 pp., 1981

2) Fitter, A. H. and HAY, R. K. : Environmental physiology of plants. 1981 (太田安定・森下豊昭・ 橘 泰憲・岩崎 誠訳：植物の環境と生理, 学会出 版センター, 381 pp., 1985)

3) JAckson, W. T.: Use of carbowaxes (polyethylene glycols) as osmotic agents. Plant Physiol., 37, 513-519, 1962

4) Jacomini, E., Bertani, A. and Mapelli, S.: Accumulation of polyethylene glycol 6000 and its effects on water content and carbohydrate level in water-stressed tomato plants. Can. J. Bot., 66, 970-973, 1987

5) JANEs, B. E.: The effect of molecular size, concentration in nutrient solution and exposure time on the amount and distribution of polyethylene glycol in pepper plants. Plant Physiol., 54, 226-230, 1974

6）神近牧男・山本太平：中国毛烏素砂漠における自然 環境について一二・三の気象・土壌特性一, 鳥取大 学砂丘研究所報告, 25, 27-35, 1986

7) KrizeK, D. T.: Methods of inducing water stress in plants. Hort Sci., 20, 1028-1038, 1985

8) LARCHER, W.: Physiological plant ecology. Springer, New York, 506 pp., 1995

9）李 雲章・李 春和 - 王 林和：臭柏生長与更新特 性初探, 内蒙古林学院学報, 18(4), 1-5, 1996

10）増田拓朗・小林達明-森本幸裕-吉川 賢: 中国毛 鳥素沙地における土壤水分条件と桿柳の根系分布 について，造園雑誌，51，126-131，1988

11) Mexal, J., Fisher, J. T., Osteryoung, J. and REID, C. P. P.: Oxygen availability in polyethylene glycol solutions and its implications in plant water relations. Plant Physiol., 55, 20-24, 1975

12) Morimoto, J. and Yoshikawa, K.: Effects of 
long-term water stress on leaf growth of seedlings of several tree species. J. Jpn. Reveget. Tech., 23(4), 228-236, 1998

13）北京大学地理系・中国科学院自然資源総合考察委員 会・中国科学院蘭州砂漠研究所 - 中国科学院蘭州水 川凍土研究所：毛烏素沙区自然条件及其改良利用, 科学出版社, 北京, 203 pp., 1983

14) Rundel, P. W. and JArrell, W. M.: Water in the environment. In: Plant Physiological Ecology (eds. R. W. Pearcy, J. Ehleringer, H. A. Mooney and P. W. Rundel). Chapman \& Hall, London, pp. 29-56, 1989

15）酒井 昭：植物の分布と環境適応一熱帯から極 地・砂漠へ一，朝倉書店，164 pp., 1995

16）蘇 世平・李 蘭暁：沙地柏生物学和生態学特性的 研究, 西北林学院学報, 2(2), 29-39, 1987

17）徳岡正三：中国の砂漠・沙地の木本植物（I ）—マツ 科, ヒノキ科, マオウ科, ヤナギ科, クルミ科, 二 レ科, クワ科, タデ科一, 京都府立大学農学部演習 林報告，33，67-103，1995

18）王 文採・鄭 万鈎・傳 立国・朱 政徳：圓柏属, 中国植物誌第 7 巻, 科学出版社, 北京, pp., 347376,1983

19）王 林和・吉川 賢・永森通雄：スギ苗木の生長に
およぼす土壤の水分条件の影響, 高知大学演習林報 告, $16,25-40,1989$

20) West, D. W., Merrigan, I. F., Taylor, J. A. and Collins, G. M.: Growth of ornamental plants irrigated with nutrient of polyethylene glycol solutions of different osmotic potentials. Plant Soil, 56, 99-111, 1980

21) Zwiazek, J. J. and Blake, T. J.: Effects of preconditioning on subsequent water relations, stomatal sensitivity and photosynthesis in black spruce. Can. J. Bot., 67, 2240-2244, 1989

22) ZwiazeK, J. J. and Blake, T. J.: Effects of preconditioning on carbohydrate and amino acid compositon of osmotically stressed black spruce (Picea mariana) cuttings. Can. J. For. Res., 20, 108-112, 1990a

23) ZWIAZEK, J. J. and Blake, T. J.: Effects of preconditioning on electrolyte leakage and lipid composition black spruce (Picea mariana) stressed with polyethylene glycol. Physiol. Plant., 79, 7177, 1990b

(1999.10. 9 受理)

\section{Summary}

Cuttings of Sabina vulgaris growing in semi arid region in China were cultivated in gravel culture for three years to investigate the phenological response under long term water stress. The osmotic potential of the water solutions was maintained at $-0.02 \mathrm{MPa},-0.10 \mathrm{MPa}$ and $-0.34 \mathrm{MPa}$ for all the experimental period by polyethylen glycol (molecular weight 6,000) treatments. In all treatments, height growth of cuttings was stopped for a short period in summer season, from June to July. The period of this dormancy became long as the osmotic potential of the water solution decreased. Although all cuttings in the -0.02 $\mathrm{MPa}$ treatment (control) were alive for three years, $25 \%$ of cuttings in other two treatments $(-0.10 \mathrm{MPa}$ and $-0.34 \mathrm{MPa}$ ) were dead at the end of the first year. Moreover, only $50 \%$ of cuttings in the $-0.34 \mathrm{MPa}$ treatment could survive until the end of the second year. It suggested that a long time was necessary to make adjustment of physiological characteristics of cuttings to severe water stress, and many cuttings were dead before got the adaptive characteristics. Sizes and shapes of dead and alive cuttings were discussed. 